\title{
Spatiotemporal characteristics of extreme precipitation and temperature: a case study in Yunnan Province, China
}

\author{
Z. X. Xu ${ }^{1,2}$, X. J. Yang ${ }^{1}$, D. P. Zuo ${ }^{1,2}$, Q. Chu ${ }^{1}$, and W. F. Liu ${ }^{3}$ \\ ${ }^{1}$ Key laboratory of Water and Sediment Sciences, Ministry of Education; College of Water Sciences, \\ Beijing Normal University, Beijing, 100875, China \\ ${ }^{2}$ Joint Center for Global Change Studies, Beijing, 100875, China \\ ${ }^{3}$ Eawag, Swiss Federal Institute of Aquatic Science and Technology, Ueberlandstrasse 133, 8600 Duebendorf, \\ Switzerland \\ Correspondence to: Z.X. Xu (zongxuexu@vip.sina.com)
}

Received: 15 April 2015 - Accepted: 15 April 2015 - Published: 11 June 2015

\begin{abstract}
Spatiotemporal characteristics of extreme precipitation and temperature in Yunnan Province, China, were analyzed by using observed daily data at 28 meteorological stations from 1958-2013 in this study. Nine extreme precipitation indices and 6 extreme temperature indices were adopted, and the tendency of those indices was investigated by using Mann-Kendal test method. In order to distinguish the spatial characteristics, the region was divided into 5 regions according to climate and topography, then the characteristics of each region were compared each other. The results indicate that changes of extreme temperature are more sensitive and significant than those of precipitation. The contribution of extreme precipitation to total precipitation presented a significant upward trend, but the annual total wet-day precipitation (PRCPTOT) did not show significant changes. Both maximum and minimum temperature showed significant increasing tendency while there was not obvious changes for precipitation. The spatial features of extreme precipitation and temperature are similar. It was noted that extreme precipitation and temperature events occurred more frequently in central region where the risk of extreme climatic events was greater than other areas.
\end{abstract}

\section{Introduction}

During the past few decades, climate change has being one of the hottest topics in hydrology. Precipitation and temperature are deemed as the most important components which can directly reflect the climate change. The frequency of extreme events was rising under the condition of global warming, especially the extreme precipitation and temperature events (Croitoru et al., 2013). Both extreme precipitation and temperature events often cause a series of extreme hydrological events, such as droughts and floods. Under this situation, the countries and regions in which major source of economic incomes depend on agriculture may be influenced obviously by the changes of precipitation and temperature (Radinović and Ćurić, 2012; Dos Santos et al., 2011) . There are already numerous studies on extreme precipitation and temperature at global, regional and national scales with the coming of 21st century (Mondal and Mujumdar, 2015; Madsen et al.,
2014; Ford, 2014). Many studies have been done at diverse regions in China (Li, 2015; Liang et al., 2014; Yu et al., 2012; Nie et al., 2012). Nevertheless, the results of these investigations have shown that the sensitivity and vulnerability for different study areas exist, especially in mountains and highland regions (Diaz et al., 2003). Therefore, further studies on extreme precipitation and temperature are considerably necessity in these regions.

The objective of this study is to choose a specific region, which is mountainous and sensitive to the precipitation and temperature, and investigate the spatiotemporal characteristics of extreme precipitation and temperature. Yunnan Province, which is located in Southwest China with high altitude and large mountainous region, is rich in biodiversity and also one of the agricultural provinces in China. Up to date, however, there have few studies on the spatiotemporal features of extreme precipitation and temperature in this 
region $(\mathrm{Li}, 2015)$ and it is noteworthy that most of the studies just focused on the average precipitation and temperature. This paper is organised as follows. Materials and methods are arranged in Sect. 2. Then Sect. 3 introduces the spatiotemporal features of precipitate and temperature, followed by summaries and conclusions in Sect. 4.

\section{Materials and methods}

\subsection{Study area description}

The total area of Yunnan Province is $394000 \mathrm{~km}^{2}$, which is located at $20^{\circ} 8^{\prime} 32^{\prime \prime}-29^{\circ} 15^{\prime} 8^{\prime \prime} \mathrm{N}$ latitude and $93^{\circ} 31^{\prime} 39^{\prime \prime}-$ $106^{\circ} 11^{\prime} 47^{\prime \prime} \mathrm{E}$ longitude. It is in the Southwest China and located in the plateau region. The south of Yunnan is near to the Bay of Bengal and South China Sea which are typical tropical oceans. This province is often influenced by the Indian monsoon, East Asian monsoon and air masses from the Qinghai-Tibet Plateau. It is, therefore, particularly sensitive and vulnerable to climate change and the characteristics of precipitation and temperature are variety within different seasons. In order to distinguish the regional characteristics of extreme climate indices, Yunnan Province can be divided into five regions (Northeast, Southeast, Centre, Northwest and Southwest) based on the features of climate and topography, as shown in Fig. 1.

\subsection{Data and methodology description}

\subsubsection{Data description}

The meterological data was downloaded from the China Meteorological Data Sharing Service System (http://cdc.cma. gov.cn/home.do), including daily precipitation, daily maximum temperature and minimum temperature. There are 35 representatively meteorological stations in Yunnan Province. Due to changes of location and lack of measurement, the data at 28 meteorological stations from 1958-2013 are finally adopted and the location of each meteorological stations is shown in Fig. 1. In order to ensure the quality of data, quality control (QC) of precipitation was made to check the daily precipitation data which is smaller than zero. The daily maximum and minimum temperature data were regarded as missing value when the daily minimum temperature was greater than maximum temperature. The homogeneity of data was assessed by using RH test method (Zhang et al., 2005; Wang, 2003), which is an R-based program and developed at the Climate Research Branch of Meteorological Service of Canada.

\subsubsection{Climate extreme indices}

There are numerous extreme precipitation indices used in existing studies, such as the indices defined according the threshold or the need at specific regions. In order to compare the extreme precipitation and temperature in Yunnan

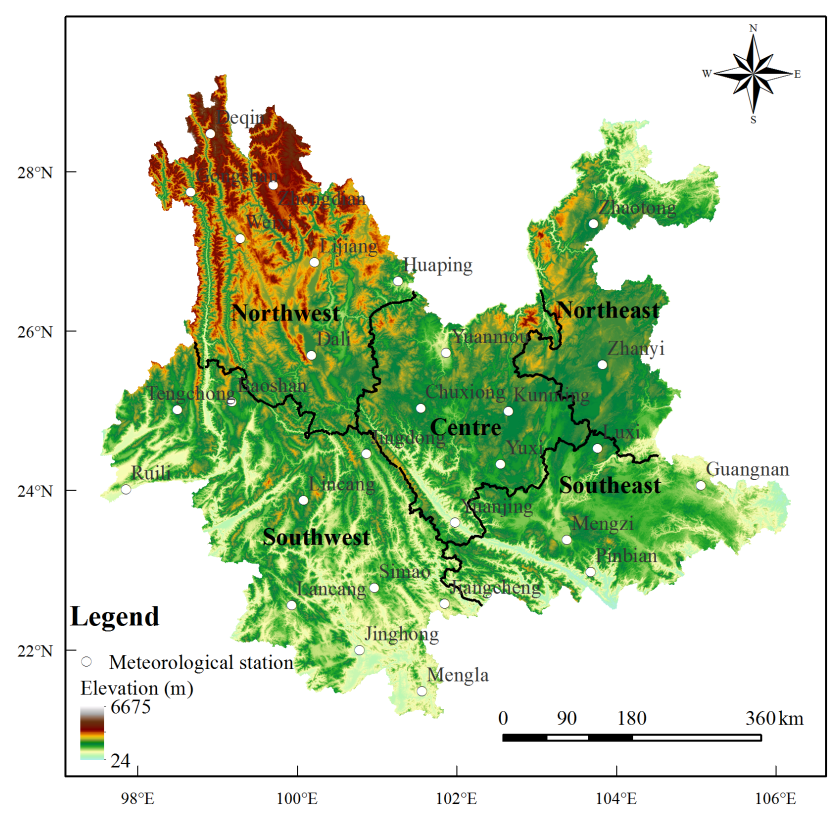

Figure 1. Spatial distribution of 28 meteorological stations in Yunnan Province, China.

Province with previous studies, nine extreme precipitation indices and 6 extreme temperature indices were adopted in this study. These indices were selected from the 27 core extreme climate indices which was developed by climate community (coordinated by the Expert Team on Climate Change Detection, Monitoring and Indices (ETCCDMI)). Details of those indices were shown in Table 1 (Nos. 1-9 are extreme precipitation indices and others are extreme temperature indices). These 15 extreme climatic indices can be divided into duration index, percentile index, threshold index and other index according to the definition of each index. These indices were estimated by RclimDex which can be download from the website (http://etccdi.pacificclimate.org/software.shtml).

\subsubsection{The method to detect the spatiotemporal variability}

Mann-Kendall test and Sen's slope estimates (Sen, 1968; Kendall, 1955) were employed to detect the tendency of each extreme climate index in Table 1 . In order to indentify whether these extreme indices show significant tendency, the significant level was set to 0.1 (the corresponding threshold value is \pm 1.64 ) in this study.

The purposes of trend detection is to explore the temporal characteristics of these extreme climate indices. However, it is also necessary to analyze the spatial distinctions of each extreme index, which will provide an overview on the region of high risk for extreme climatic events. In order to show the spatial characteristics of the typical indices, the Inverse Distance Weighting (IDW) method is adopted to interpolate the index value of decadal average at 28 meteorological stations. 
Table 1. List of extreme precipitation and temperature indices.

\begin{tabular}{|c|c|c|c|c|}
\hline No. & Index & Indicator name & Definitions & Units \\
\hline 1 & SDII & $\begin{array}{l}\text { Simple daily intensity } \\
\text { index }\end{array}$ & $\begin{array}{l}\text { Annual total precipitation divided by the number } \\
\text { of wet days (defined as } \mathrm{PRCP}>=1.0 \mathrm{~mm} \text { ) in the year }\end{array}$ & $\mathrm{mm}_{\text {day }}{ }^{-1}$ \\
\hline 2 & $\mathrm{R} 10$ & $\begin{array}{l}\text { Number of heavy } \\
\text { precipitation days }\end{array}$ & Annual count of days when PRCP $>=10 \mathrm{~mm}$ & days \\
\hline 3 & $\mathrm{R} 20$ & $\begin{array}{l}\text { Number of very heavy } \\
\text { precipitation days }\end{array}$ & Annual count of days when PRCP $>=20 \mathrm{~mm}$ & days \\
\hline 4 & $\mathrm{R} 25$ & $\begin{array}{l}\text { Number of days } \\
\text { above } n n \mathrm{~mm}\end{array}$ & Annual count of days when PRCP $>=25 \mathrm{~mm}$ & days \\
\hline 5 & $\mathrm{CDD}$ & Consecutive dry days & $\begin{array}{l}\text { Maximum number of consecutive days with } \\
\mathrm{RR}<1 \mathrm{~mm}\end{array}$ & days \\
\hline 6 & CWD & Consecutive wet days & $\begin{array}{l}\text { Maximum number of consecutive days with } \\
\mathrm{RR}>=1 \mathrm{~mm}\end{array}$ & days \\
\hline 7 & R95p & Very wet days & Annual total PRCP when RR > 95th percentile & $\mathrm{mm}$ \\
\hline 8 & R99p & Extremely wet days & Annual total PRCP when RR > 99th percentile & $\mathrm{mm}$ \\
\hline 9 & PRCPTOT & $\begin{array}{l}\text { Annual total wet-day } \\
\text { precipitation }\end{array}$ & Annual total PRCP in wet days $(\mathrm{RR}>=1 \mathrm{~mm})$ & $\mathrm{mm}$ \\
\hline 10 & CSDI & $\begin{array}{l}\text { Cold spell duration } \\
\text { indicator }\end{array}$ & $\begin{array}{l}\text { Annual count of days with at least } 6 \text { consecutive } \\
\text { days when } T N \text { (daily maximum) }<10 \text { th percentile }\end{array}$ & days \\
\hline 11 & WSDI & $\begin{array}{l}\text { Warm spell duration } \\
\text { indicator }\end{array}$ & $\begin{array}{l}\text { Annual count of days with at least } 6 \text { consecutive } \\
\text { days when } T X \text { (daily maximum) }>90 \text { th percentile }\end{array}$ & days \\
\hline 12 & DTR & $\begin{array}{l}\text { Diurnal temperature } \\
\text { range }\end{array}$ & Monthly mean difference between $T X$ and $T N$ & ${ }^{\circ} \mathrm{C}$ \\
\hline 13 & SU25 & Summer days & Annual count when $T X$ (daily maximum) $>25^{\circ} \mathrm{C}$ & days \\
\hline 14 & TR20 & Tropical nights & Annual count when $T N$ (daily minimum) $>20^{\circ} \mathrm{C}$ & days \\
\hline 15 & ETR & $\begin{array}{l}\text { Annual temperature } \\
\text { range }\end{array}$ & Difference between maximum $T X$ and $T N$ & ${ }^{\circ} \mathrm{C}$ \\
\hline
\end{tabular}

PRCP is the daily precipitation amount; $\mathrm{RR}_{i j}$ is the daily precipitation amount on day $i$ in period $j$.

\section{Results analysis and discussions}

\subsection{Temporal features of extreme precipitation and temperature}

\subsubsection{Analysis on extreme precipitation}

There are almost $71-93 \%$ of stations without significant tendency of changes. It is apparent from Table 2 that most of stations did not show significant tendency. However, comparing with these 9 extreme precipitation indices, CDD, R95p, R99p and SDII show more stations with significant increasing tendency, especially CDD. On the contrary, CWD, R10, R20 and annual total wet-day precipitation (PRCPTOT) show more stations with significant decreasing tendency.

According to the results on duration indices of precipitation, the value of CDD is greater than that of CWD and this indicates that the duration of drought is comparatively longer.
CDD showed an increasing trend but the CWD showed the negative trend. The annual average value of CDD was 52 days, and it was reduced at 1 day per decade. At the same time, CWD showed a significant negative trend at $1 \%$ of significant level, and the detail of CWD was shown in Fig. 2.

Threshold indices for precipitation include R10, R20 and $\mathrm{R} 25$. A decreasing trend is apparent for both $\mathrm{R} 10$ and $\mathrm{R} 20$. Conversely, R25 showed an increasing tendency. There were no significant trend changes for R10, R20 and R25.

The percentile indices of precipitation consist of R95p and R99p in this study. These indices can indicate the amount of the extreme precipitation and illustrate the frequency of flood. The annual average value of R95p is $269 \mathrm{~mm}$, which is near a quarter of annual total wet-day precipitation (PRCPTOT). But the tendency of R95p did not pass the test at $10 \%$ of significant level. The mean annual value of R99p was around $79 \mathrm{~mm}$, and it showed a significant upward ten- 

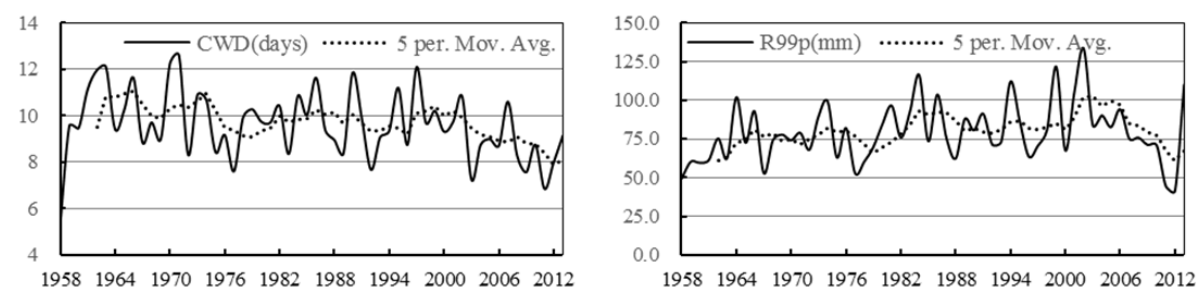

Figure 2. Trend of annual average extreme precipitation indices (CWD/R99p) in Yunnan Province from 1958 to 2013. (Dashed line is the 5-years moving average.)
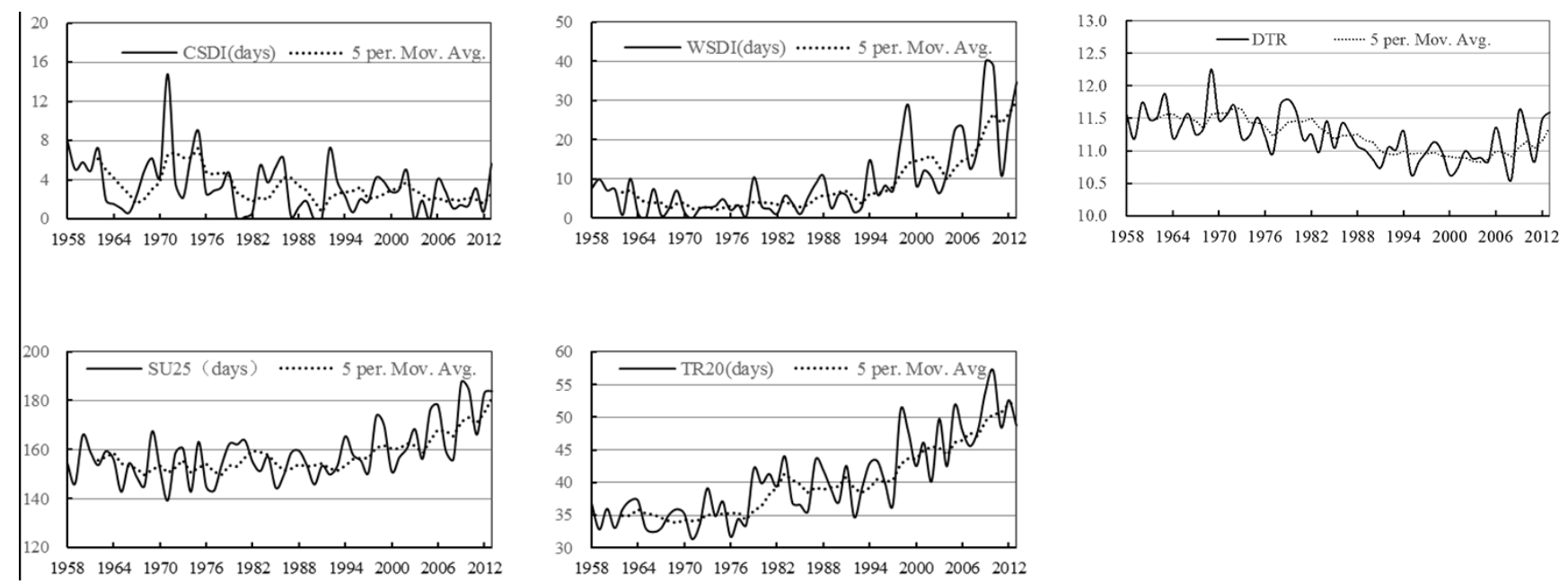

Figure 3. Trend of annual average extreme temperature indices (CSDI, WSDI, DTR, SU25 and TR20) in Yunnan Province from 1958 to 2013. (Dashed line is the 5-years moving average.)

dency at $5 \%$ of significant level. The fluctuated feature of R99p was displayed in Fig. 2.

During the period of 1958-2013, the average annual value of SDII was fluctuating between 9.5 and $12.0 \mathrm{~mm} \mathrm{day}^{-1}$. There was a statistically upward tendency of SDII. However, this trend was not statistically significant. The annual average value of PRCPTOT is $1104 \mathrm{~mm}$, and a downward tendency was detected with a $10 \%$ of significant level.

The indices (CWD, R10, R20 and PRCPTOT), which can reflect the change of the amount of precipitation and the duration of precipitation, showed a decreasing trend, particularly the CWD had passed the test at the significant level of $1 \%$. Comparing the trend changes of all extreme precipitation indices in Yunnan Province, it is worthy to note that CWD showed significantly decreasing tendency in five regions. At the same time, other precipitation indices showed positive trend, especially the significance of R99p was at the $5 \%$ of significant level. From these results, it is possible to show that the drought risk in Yunnan Province is greater than that of flood. However, extreme precipitation showed a continuous increasing tendency.

\subsubsection{Analysis on extreme temperature}

In order to investigate the temporal changes of the 6 indices, all average values of each index was estimated on the basis of the values at 28 meteorological stations. The tendency of each index was detected. CSDI and DTR showed significant negative trend at $5 \%$ of significant level, particularly the DTR passed the significant level of $1 \%$. ETR also showed a decreasing tendency without significance. WSDI, SU25 and TR20 showed significant increasing during the period of 1958-2013, and the significant level is 1\%o. Figure 3 showed the average values of each index with significant changes of tendency. It is obvious that the value of CSDI is obviously smaller than WSDI since the 1990s. WSDI, SU25 and TR20 showed increasing tendency with the same magnitude ( 3 days $/ 10$ a). It can be seen that the increasing range of maximum temperature was smaller than that of minimum temperature. Therefore, DTR presented a significant negative trend.

In order to give an overall analysis on these extreme temperature indices, the number of the meteorological stations with significant changes of trend was calculated in each region. Most of the extreme temperature indices showed that more than half of meteorological stations showed signifi- 
Table 2. Number of stations with significant increasing ( 0.1 of significance level) for annual extreme precipitation indices during the period of 1958-2013.

\begin{tabular}{lccc}
\hline Index & $\begin{array}{c}\text { Significant } \\
\text { increase }\end{array}$ & $\begin{array}{c}\text { Insignificant } \\
\text { increase/ } \\
\text { decrease }\end{array}$ & $\begin{array}{c}\text { Significant } \\
\text { decrease }\end{array}$ \\
\hline CDD & 6 & 21 & 1 \\
CWD & 0 & 20 & 8 \\
R10 & 0 & 24 & 4 \\
R20 & 1 & 22 & 5 \\
R25 & 2 & 22 & 4 \\
R95p & 2 & 25 & 1 \\
R99p & 2 & 25 & 1 \\
SDII & 2 & 25 & 1 \\
PRCPTOT & 0 & 24 & 4 \\
\hline
\end{tabular}

cant trend (Table 3). CSDI and WSDI are duration index, and showed the opposite tendency. Comparing the results of CSDI and WSDI, it is obvious that more stations of WSDI showed significant upward tendency. At each region in Yunnan Province, more than half of the stations displayed significantly increasing tendency. However, the results of CSDI indicated that only one station was found to have significant upward trend in the central region. Other stations with significant tendency showed downward trend. More striking conclusion, according to the results from two duration indices, is that Yunnan Province was experiencing longer warm duration and shorter cold duration.

The threshold extreme temperature index includes SU25 and TR20. Interestingly, SU25 and TR20 showed similar spatial features on trend according to the calculated results. There are more meteorological stations showing significant positive trend in Northeast and Southwest regions.

Both DTR and ETR showed the changes of temperature at different time scales. The numbers of stations with significant increasing trend are same in each region according to the results of DTR and ETR. The temperature showed more sensitive decreasing trend in both Centre and Southwest regions.

Average temperature in Northwest region is the lowest in Yunnan Province and the highest average temperature is in the Southwest region. According to the statistical results from 6 extreme temperature indices in five regions, the variable features in Northwest and Southwest regions showing significant increasing trend of temperature are more obvious than that in other regions. Therefore, both Northwest and Southwest regions are more crucial to contribute for the upward trend of temperature in Yunnan Province. It is also worthy to note that it may be beneficial for the growth of crops with the increase of temperature. However, the impact on the yield of crops is unclear due to this change of temperature.
Table 3. Number of stations with significant increasing ( 0.1 of significance level) for annual extreme temperature indices during the period of 1958-2013.

\begin{tabular}{lrrr}
\hline Index & $\begin{array}{r}\text { Significant } \\
\text { increase }\end{array}$ & $\begin{array}{r}\text { Insignificant } \\
\text { increase/ } \\
\text { decrease }\end{array}$ & $\begin{array}{c}\text { Significant } \\
\text { decrease }\end{array}$ \\
\hline CSDI & 1 & 17 & 10 \\
WSDI & 23 & 5 & 0 \\
DTR & 3 & 10 & 15 \\
SU25 & 20 & 8 & 0 \\
TR20 & 16 & 11 & 1 \\
ETR & 1 & 12 & 15 \\
\hline
\end{tabular}

\subsection{Spatial characteristics of precipitation and temperature}

It can be seen that two extreme precipitation indices (CWD and R99p) and five extreme temperature indices (CSDI, WSDI, DTR, SU25 and TR20) showed significant changes of trend. In order to reveal the spatial characteristics of extreme precipitation and temperature in detail, these 7 indices were adopted to investigate the spatial features during the past five decades.

The spatial distribution of CWD and R99p was shown in Fig. 4. The value of CWD fluctuated from 5 to 20 days. The CWD showed decreasing tendency in Southwest, Northwest, Southeast, Centre and Northeast regions. The mean decadal value of CWD showed consistently decreasing tendency except the 1970s. The minimum value extended from Centre region to Northeast region. The magnitude of R99p ranges from 17.9 to $193.0 \mathrm{~mm}$. The maximum value of $\mathrm{R} 99 \mathrm{p}$ occurred from the southeast of the Northwest region to circumambient area. It is apparent that R99p was consistently increasing except the 1970s. It can be inferred that Northwest and Centre regions in Yunnan Province may have greater risk of extreme precipitation than other regions.

The spatial pattern of five extreme temperature indices was displayed in Fig. 5. As for the spatial distribution of CSDI during the past five decades, five regions showed obvious negative trend. Meanwhile, the decreasing trend in Northwest region was most apparent in Yunnan Province. The most interesting result for WSDI is that the WSDI showed increasing tendency since 1990, especially the increasing trend in Northwest, Southwest and Centre regions. The value of DTR ranged from 1.3 to $15^{\circ} \mathrm{C}$. Northwest, Southwest and Southeast regions showed consistent decreasing trend for DTR during the past five decades. However, the value of DTR in Centre region increased from the 1960s to the 1970s, and the trend was negative since the 1980s. The magnitude of DTR is from 6.1 to $15^{\circ} \mathrm{C}$ in most regions of Yunnan Province, and the DTR in Northeast region was quite stable, which always kept the value around $11^{\circ}$ during the past five decades. Comparing the spatial pattern of SU25 and TR20, it can be 

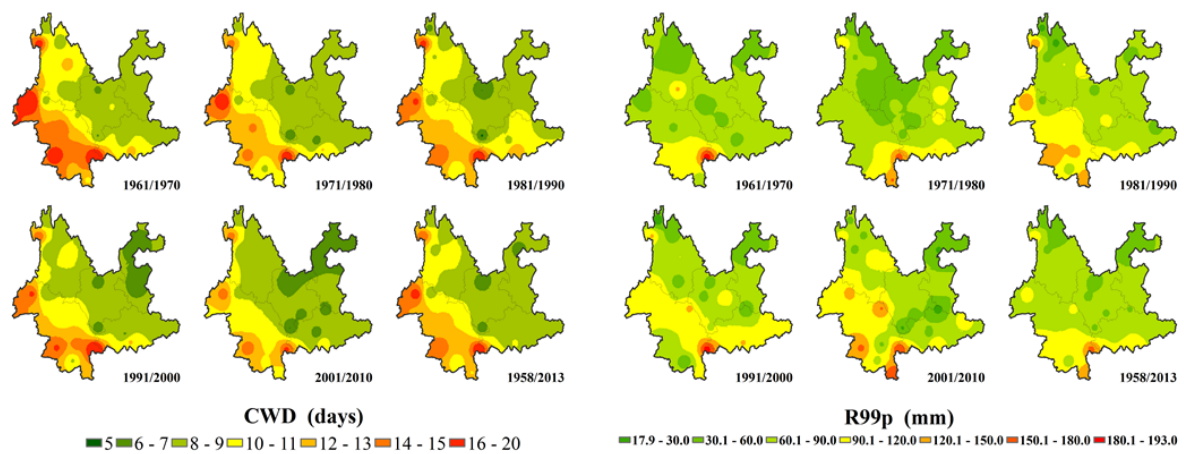

(a)

(b)

Figure 4. Spatial distribution of decadal mean extreme precipitation indices in Yunnan Province during the period of 1958-2013 (a) CWD and (b) R99p.

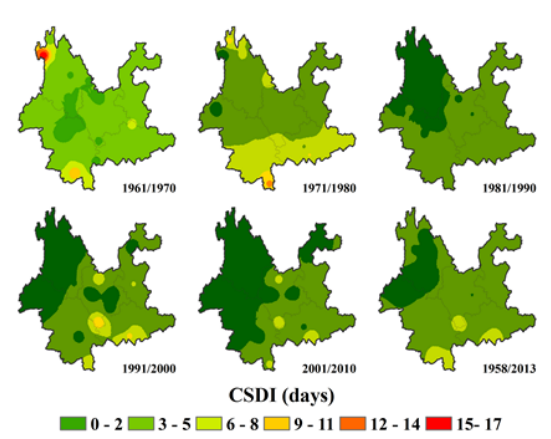

(a)

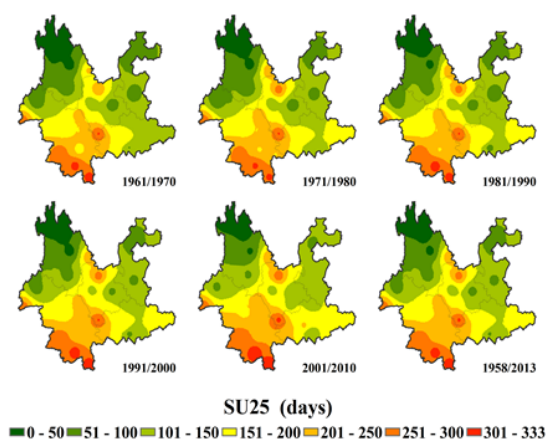

(d)

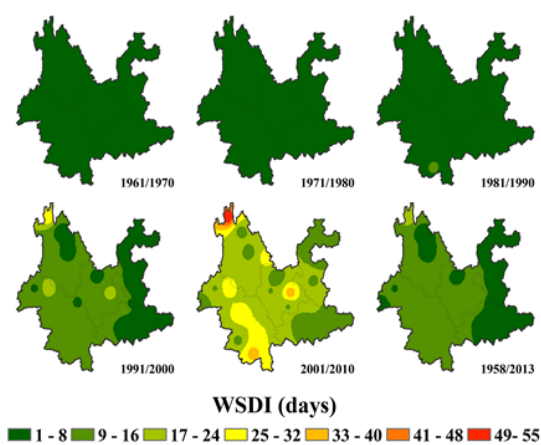

(b)

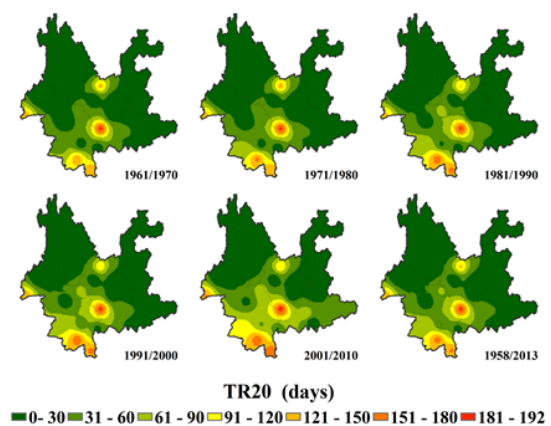

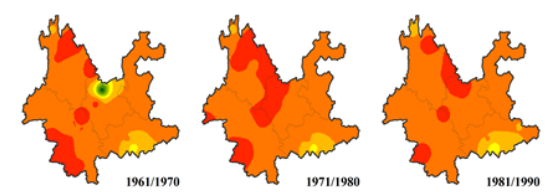
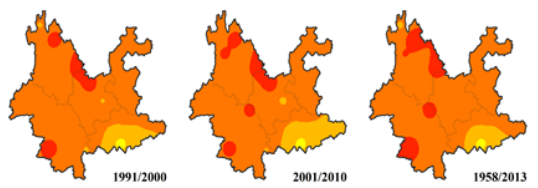

DTR ( $\left.{ }^{\circ} \mathrm{C}\right)$

(c)

(e)

Figure 5. Spatial distribution of decadal mean extreme temperature indices in Yunnan Province during the period of 1958-2013 (a) CSDI, (b) WSDI, (c) DTR, (d) SU25 and (e) TR20.

seen that both SU25 and TR20 are the same order ranking the maximum value in Southwest region, then the Centre region, and then the Southeast region, Northeast region, and the minimum appeared in the Northwest region.

\section{Conclusions}

This study shows that there are two extreme precipitation indices (CWD, R99p) which showed significant tendency. 
These results suggest that the continuous wed days in Yunnan Province showed remarkable decreasing while the intensity of precipitation become stronger and more concentrated with the time. Extreme temperature indices showed more frequent fluctuation and had significant tendency comparing with extreme precipitation. The results for extreme temperature indices manifested that all five indices showed significant tendency except ETR. Both maximum and minimum temperature showed marvellous upward trend, especially minimum temperature. Spatially, both Northwest and Centre regions suffered heavier precipitation than other region of Yunnan Province during the period of 1958-2013. On the other hand, the Centre region showed a greater risk with upward tendency of temperature.

Acknowledgements. This study is financially supported by the Key Consulting Project of the Chinese Academy of Engineering (No. 2012-ZD-13) and Special Fund for Research on Public Interests, Ministry of Water Resources (No. 201401036). The RHtests and RClimDex is developed and maintained by Xuebin Zhang and Feng Yang at the Climate Research Branch of Meteorological Service of Canada.

\section{References}

Croitoru, A. E., Chiotoroiu, B. C., Todorova, V. I., and Torica, V.: Changes in precipitation extremes on the Black Sea Western Coast, Global Planet. Change, 102, 10-19, doi:10.1016/j.gloplacha.2013.01.004, 2013.

Diaz, H. F., Grosjean, M., and Graumlich, L.: Climate variability and change in high elevation regions: Past, present and future, Climatic Change, 59, 1-4, doi:10.1023/A:1024416227887, 2003.

Dos Santos, C. A. C., Neale, C. M. U., Rao, T. V. R., and Da Silva, B. B.: Trends in indices for extremes in daily temperature and precipitation over Utah, USA, Int. J. Climatol., 31, 1813-1822, doi:10.1002/joc.2205, 2011.

Ford, T. W.: Precipitation anomalies in Eastern-Central Iowa from 1640-Present, J. Hydrol., 519, 918-924, doi:10.1016/j.jhydrol.2014.08.021, 2014.
Kendall, M. G.: Rank correlation methods, C. Griffin, London, vii, 196 pp., 1955.

Li, Z.: Spatial and Temporal Variation of Temperature and Precipitation in Southwestern China, in: Study on Climate Change in Southwestern China, Springer, Berlin, Heidelberg, 61-100, 2015.

Liang, K., Bai, P., Li, J., and Liu, C.: Variability of temperature extremes in the Yellow River basin during 1961-2011, Quatern. Int., 336, 52-64, doi:10.1016/j.quaint.2014.02.007, 2014.

Madsen, H., Lawrence, D., Lang, M., Martinkova, M., and Kjeldsen, T. R.: Review of trend analysis and climate change projections of extreme precipitation and floods in Europe, J. Hydrol., 519, 3634-3650, doi:10.1016/j.jhydrol.2014.11.003, 2014.

Mondal, A. and Mujumdar, P. P.: Modeling non-stationarity in intensity, duration and frequency of extreme rainfall over India, J. Hydrol., 521, 217-231, doi:10.1016/j.jhydrol.2014.11.071, 2015.

Nie, C. J., Li, H. R., Yang, L. S., Ye, B. X., Dai, E. F., Wu, S. H., Liu, Y., and Liao, Y. F.: Spatial and temporal changes in extreme temperature and extreme precipitation in Guangxi, Quatern. Int., 263, 162-171, doi:10.1016/j.quaint.2012.02.029, 2012.

Radinović, D. and Ćurić, M.: Some evidence on European monsoon existence, Theor. Appl. Climatol., 110, 11-15, doi:10.1007/s00704-012-0609-y, 2012.

Sen, P. K.: Estimates of the Regression Coefficient Based on Kendall's Tau, J. Am. Stat. Assoc., 63, 1379-1389, 1968.

Wang, X. L.: Comments on "Detection of undocumented changepoints: A revision of the two-phase regression model", J. Climate, 16, 3383-3385, doi:10.1175/15200442(2003)016<3383:Codouc>2.0.Co;2, 2003.

Yu, L. L., Xia, Z. Q., Cai, T., and Guo, L. D.: Variations of Temperature, Precipitation, and Extreme Events in Heilongjiang River, Procedia Eng., 28, 326-330, doi:10.1016/j.proeng.2012.01.727, 2012.

Zhang, X. B., Aguilar, E., Sensoy, S., Melkonyan, H., Tagiyeva, U., Ahmed, N., Kutaladze, N., Rahimzadeh, F., Taghipour, A., Hantosh, T. H., Albert, P., Semawi, M., Ali, M. K., Al-Shabibi, M. H. S., Al-Oulan, Z., Zatari, T., Khelet, I. A., Hamoud, S., Sagir, R., Demircan, M., Eken, M., Adiguzel, M., Alexander, L., Peterson, T. C., and Wallis, T.: Trends in Middle East climate extreme indices from 1950 to 2003, J. Geophys. Res.-Atmos., 110, D22104, doi:10.1029/2005jd006181, 2005. 